\title{
Safety and Health Issues in Selected Schools of Chibombo District in Central Province of Zambia
}

\author{
Kaiko Mubita ${ }^{1}$, Timothy K. Phiri ${ }^{2}$, Pauline N. Monde ${ }^{3}$, Steria M. Simooya ${ }^{4}$ \\ The University of Zambia, School of Education \\ Department of Language and Social Sciences Education, Lusaka, Zambia
}

\begin{abstract}
Safety and health management in schools is a growing concern in Zambia. Media reports on dilapidated infrastructure, unhealthy conditions and other cases of insecurity in schools have been on the rise. According to United Nations Children's Fund (UNICEF, 2009) academic attainment is regarded as a decisive factor that determines educational quality. Therefore, in pursuing such academic attainment, children have the right to learn in a safe and healthy environment. With reference to the argument by UNICEF, this paper explored safety and health issues in selected schools of Chibombo District in Central province of Zambia. Using purposive and simple random sampling, a sample of fifty stakeholders in randomly selected schools of Chibombo district was selected. This sample comprised teachers, pupils and auxiliary staff in the selected schools. Data was collected using unstructured interviews and focus group discussion. Data collected was analyzed using descriptive statistics and thematic analysis. This paper established that the selected schools faced many safety and health challenges. This study established that as much as the selected schools in Chibombo district had put in place safety and health measures, there were still outstanding safety and health concerns. It is therefore recommended that the government should provide safe and health school environments through appropriate frameworks, guidance and legislation.
\end{abstract}

Keywords: Safety, health, safety and health issues.

\section{INTRODUCTION}

School safety and health is an integral and indispensable component of the teaching and learning process. According to Squelch (2001) a clean and safe environment is conducive to education and has security of property, well cared for facilities, furniture and equipment, clean toilets, water and green environment and absence of harassment. The Independent Project Trust (IPT, 1999) confirms this by stating that a secure school environment has a very low risk of physical, emotional and psychological injury to its occupants. IPT (1999) further argues that a safe school is therefore a healthy school.

The Ministry of Education, Zambia (1996) also endorses the role of the school as a health affirming and health promoting institution for all pupils, and through them, for the community from which the pupils come and for the families which they eventually establish. The ministry also recognises that good pupil, community and societal health are dependent on a healthy and safe environment. In spite of the importance of school safety and health as explained above, the state of safety and health in Zambian schools is still poor. This poor state of safety and health conditions in Zambian school is highlighted by media reports. Headlines like; "Kalingalinga pupils continue to learn under poor sanitary conditions" (Post Newspaper, 17th April, 2014), "Sefula school grapples with dilapidated infrastructure"(Muvi TV, October 17, 2013) and " Chingola pupil pulls out gun, threatens to shoot teacher " (Post Online, 17th April, 2014) are becoming common in various media in Zambia. These reported incidents present a picture of unsafe, insecure and unhealthy school environments in Zambia. Against this background, this study investigated safety and health issues in selected schools in Chibombo District of Central Province of Zambia. Sustainable mitigation measures to identified safety and health issues in selected schools of Chibombo district have been suggested to this effect.

\section{AIM}

The aim of the study was to assess the state of safety and health in selected schools of Chibombo district of central Zambia. The study also aimed at investigating safety and health challenges faced by surveyed schools and then suggest sustainable mitigations measures to address the identified challenges in those schools. 


\section{RESEARCH QUESTIONS}

The above aim was addressed through the following specific questions:

(a) What is the state of safety and health of selected schools of Chibombo district of Central Province?

(b) What are the safety and health challenges in selected schools of Chibombo district of Central Zambia?

(c) What sustainable mitigation measures can be proposed to address the challenges of safety and health identified in selected schools of Chibombo district of Central Zambia?

\section{Conceptual and Theoretical Frameworks}

\subsection{Conceptual Framework}

This study was guided by what was thought to be a logical process of managing safety and health issues in the context of selected schools in Chibombo district. It is argued that for environments in these selected schools of Chibombo district to be safe and healthy, each school should have a safety and health policy, be prepared for emergencies, integrate safety and health issues into planning and carry out risk assessments and audits regularly. This practice may translate into increased pupil morale, enrolment, retention and completion as well as increased staff morale and retention among other likely benefits.

Figure 1 summarises the concept of safe and health school environment in the context of this study.

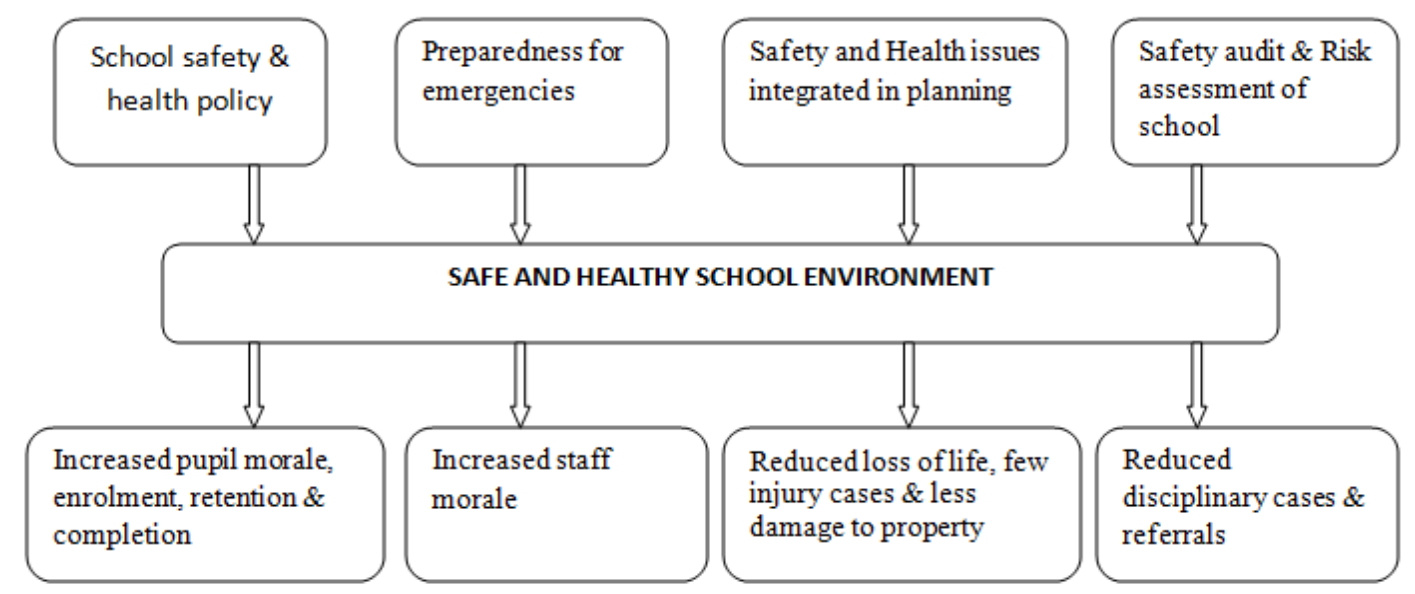

Figure1. Conceptual Frame work for a Safe and Health School

Source: (Mubita, 2016)

As presented by figure 1, safe and health school environments should develop safety and health policies, prepared for emergencies, integrate safety and health issues in planning and carry out risk assessments and audits; then, the schools are likely to have increased pupil morale, enrolment, retention and completion among other likely benefits (Mubita, 2016).

\subsection{Theoretical Framework}

This study was operationalised through Maslow's Hierarchy of Needs theory. Maslow proposed that motivation is the result of a person's attempt at fulfilling five basic needs: physiological, safety, social, esteem and self-actualization. According to Maslow, these needs can create pressures that can influence a person's behavior. Maslow's theory of motivation states that when a lower need is satisfied, the next highest need becomes dominant and the individuals' attention is turned to satisfying this higher need (McLeod, 2014). In the context of this study, safety needs in this theory include those needs that provide people in school environments with a sense of security and well-being. Personal safety and security, good health and protection from accidents, harm and their adverse affects are all included in safety needs hierarchy. This theory formed an important base for this study because it identified safety needs as being important to the well-being of stakeholders in selected schools of Chibombo district. After meeting the physiological needs, the stakeholders in these schools required 
assurance that their safety and security needs would be addressed. It was therefore, imperative that these schools fostered safe and health environments to facilitate increased learners enrolment, retention, completion and hence attainment of quality education. Figure 2 below shows a summary of Maslow's Hierarchy of Needs model.

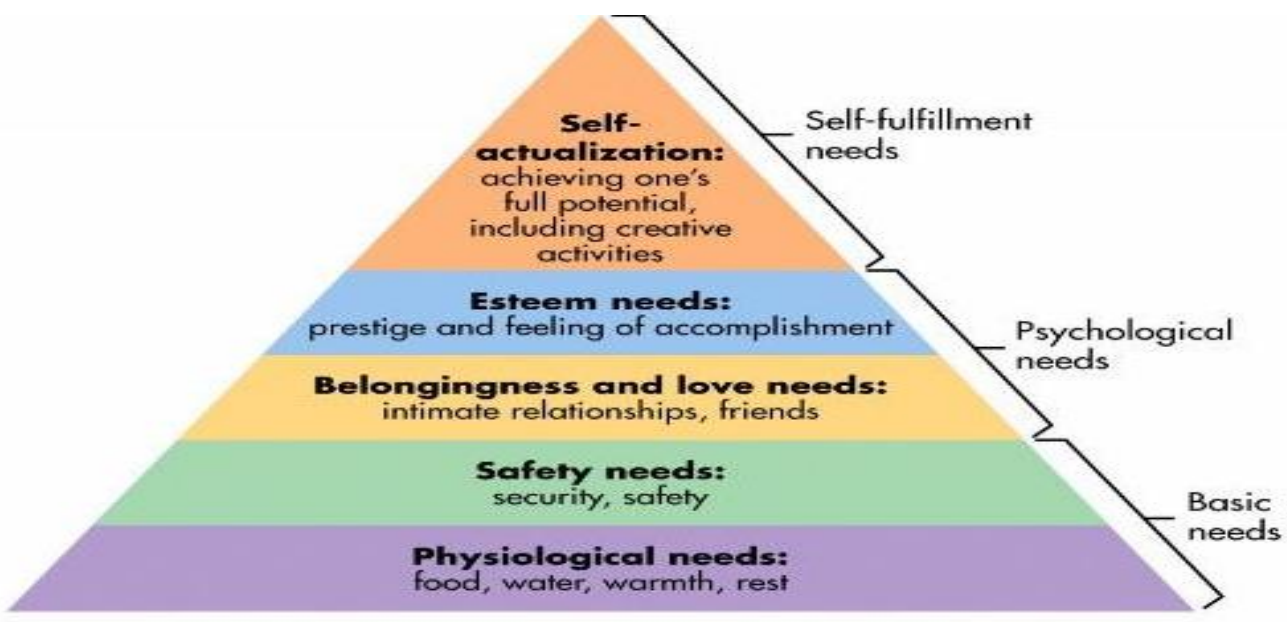

Figure2. Maslow's Hierarchy of Needs model

Source: McLeod (2014)

\section{AN OVERVIEW OF LITERATURE}

Safety and health of learners is central to the provision of quality education in any country. Various studies regarding school safety and health have been conducted both locally and globally as elaborated herein; Oluremi (2005) conducted a study on creating a friendly school learning environment for Nigerian children. In this study, the areas included were classroom environment, provision of infrastructural facilities, and teacher pupil interaction in the classroom setting. The study found that $25 \%$ of the schools selected were not child friendly because they lacked infrastructural facilities like desks, toilet facilities, tables, chairs and desks among others. According to Mwangi (2008) learning institutions in Kenya have continued to experience different disasters emanating from inappropriate school physical infrastructure among other factors. Cash (1993) explored the relationship between safety of school facilities and student achievement and behavior in small rural high schools in the commonwealth of Virginia. The researcher found that students' achievement scores were higher in schools with better and safe building condition. Students' achievement was related more to the condition of the building while student behavior was related more to the structural condition of the building. The researcher also found that varying climate control, locker condition, and graffiti were factors that were positively related to the student's achievement. These findings underscore the importance of the current study in the sense that if selected schools in Chibombo district enhanced safety of infrastructure learners' achievement and desired behavior would be enhanced. The United Nations Educational, Scientific and Cultural Organisation (UNESCO, 2004) also emphasise the importance of school safety by stating that, upgrading and construction of schools that will be relatively safe during the occurrence of disasters should be part of every nation's long term planning.

\section{Methodology AND RESEARCH APPROACH}

This research is situated in the constructivist paradigm. Constructivism grew out of the philosophy of Edmund Husserl's phenomenology and Wilhelm Dilthey's and other German philosophers' study of interpretive understanding called hermeneutics (Mertens, 2005, citing Eichelberger, 1989). Constructivist approaches to research seek to understand the world of human experience (Cohen \& Manion, 1994). According to Merten (2005) reality is socially constructed. The constructivist researcher relies upon the "participants' views of the situation being studied" (Creswell, 2003, p.8) and recognises the impact on the research of their own background and experiences. In trying to manage safety and health issues in their respective schools, the stakeholders in selected schools of Chibombo district will socially come up with mitigation measures according to their experiences. These interpretations and socially constructed ideas in managing safety and health in their schools is part of the knowledge being pursued in this study. 
The study utilised descriptive survey research design that mainly used qualitative research methods. Unstructured interviews and focus group discussions were used as data collection methods. Using purposive sampling and simple random sampling techniques, a sample size of 50 school stakeholders in randomly selected schools in Chibombo district was targeted. The sample comprised teachers, pupils and auxiliary staff. A total of 8 schools were selected for this study, that is, 3 secondary schools and 5 primary schools. Thematic data analysis was utilised for this study.

\section{RESUltS AND DisCUSSION}

\subsection{Safety and Health Status of Selected Schools of Chibombo District of Central Province of Zambia}

This study explored the state of safety and health of selected schools of Chibombo district in central province of Zambia. In doing so, different components of school environments were assessed to give researchers the state of safety and health. To this effect, the following components were assessed:

\section{(a) Safety and health status of classrooms}

Classrooms are centres of learning in all schools. Therefore, this study assessed the state of safety and health of classrooms under which pupils learn in selected schools of Chibombo district of central province of Zambia. Respondents rated the safety and health condition of classrooms as presented in figure 3 .

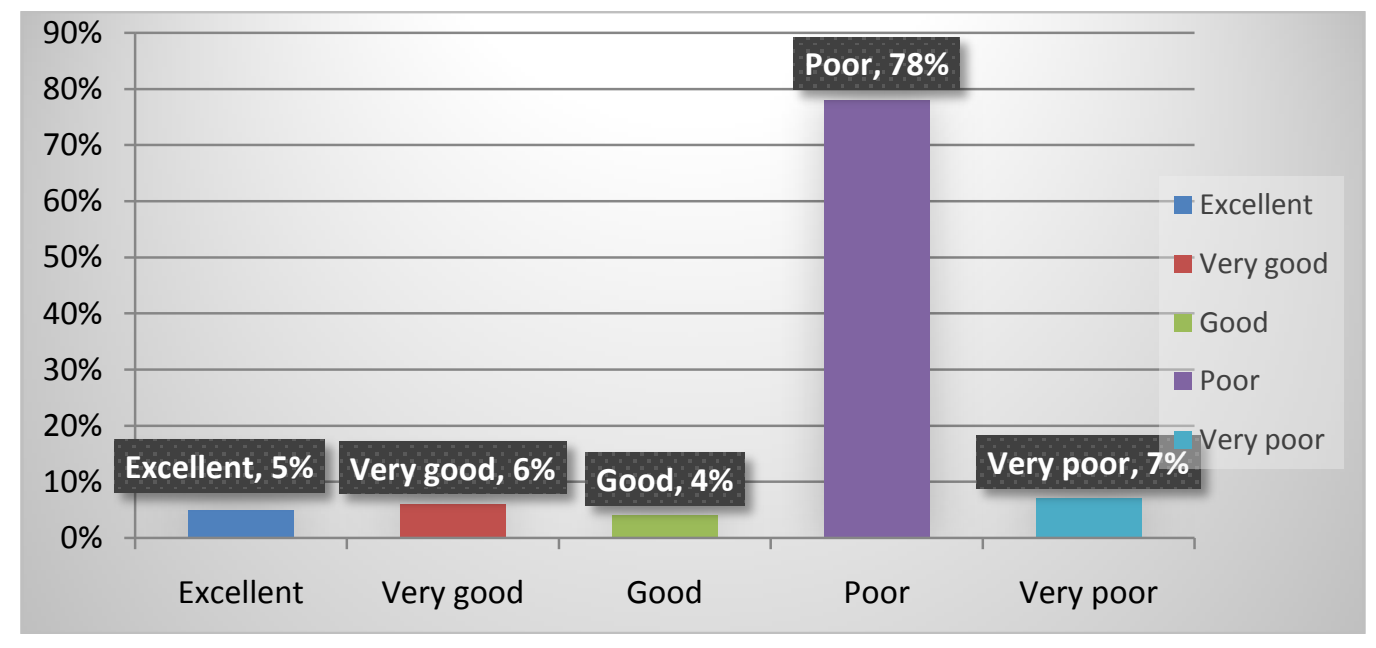

Figure3. Safety and health status of classrooms

Source: (Field data, 2014)

As presented in figure 3, most of the respondents rated the status of classrooms as poor (78\%). $7 \%$ of respondents rated safety and health status of classrooms as very poor, $6 \%$ as very good, $4 \%$ as good and $5 \%$ excellent. This kind of distribution indicates that classrooms in selected schools of Chibombo district were not in good condition for teaching and learning. The classrooms were dilapidated, with broken windows, cracked walls and floors. Other classrooms had mould and fungi with leaking roofs. All these conditions were likely to affect teaching and learning activities in these schools. This is because instead of concentrating on learning and teaching, the pupils and staff were likely to concentrate on their individual safety and health as opposed to paying attention to teaching and learning. This could affect the pupils' educational outcomes. This scenario could also lead to low attendance rates among pupils in these schools. This is in correlation with Romina's (2014) study on students' perception of the condition of their classroom's physical learning environment and its impact on their learning and motivation. The study revealed that the condition of classroom physical learning environment had great impact on students' learning and motivation including the motivation to actively participate in academic activities; it can influence their personal behavior and their school attendance.

\section{(b) Safety and health status of sanitation infrastructure}

This study also investigated safety and health status of sanitation infrastructure in selected schools of Chibombo district of central province of Zambia. Respondents in schools rated safety and health status of sanitation infrastructure as presented in figure 4. 


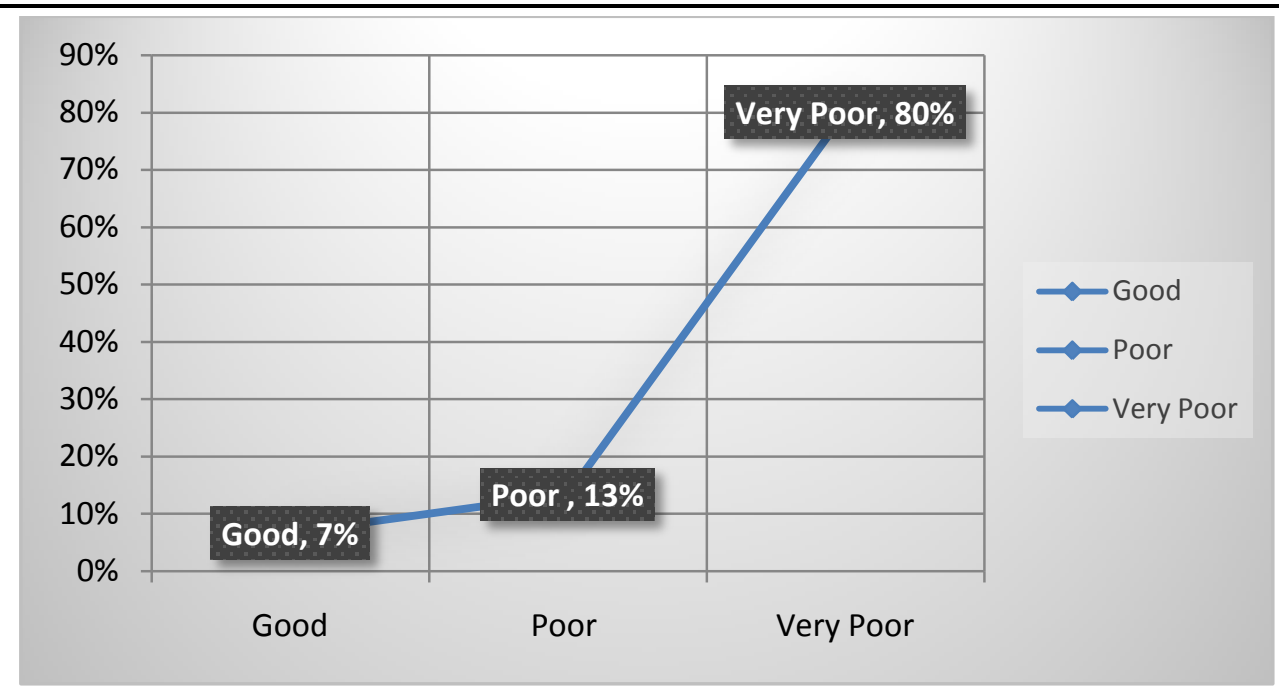

Figure4. Safety and health status of sanitation infrastructure

Source: (Field data, 2014)

As presented in figure 4, sanitation infrastructure in selected schools of Chibombo district was in very poor condition $(80 \%) .13 \%$ of respondents indicated that sanitation infrastructure was in poor condition while $7 \%$ of the respondents rated sanitation infrastructure as good. This in correlation with UNICEF (2010) assertion that millions of children in the developing world go to schools with no drinking water or clean latrines. UNICEF (2010) also contends that every child has the right to be in a school that offers safe water, healthy sanitation and hygiene education. Safe and healthy school sanitation infrastructure can create improved learning environments, thereby facilitating increased attendance and retention of pupils and staff in selected schools of Chibombo district. The impact of poor school sanitation infrastructure is most pronounced among girls, when their special needs of adequacy and privacy are not catered for. This is supported by Fentiman, Hall and Bundy, (1999) who argue that reasons for high dropout rates, particularly among pubescent-age girls are attributed to the absence of sanitation facilities in many schools worldwide. Lidonde (2004) is also worried that poor sanitation infrastructure in schools may cause girls to miss school on their menstruation days and then drop out from school in the long run.

\section{(c) State of water supply in schools}

This study also investigated the state of water supply in selected schools of Chibombo district. This is because poor water supply in schools may lead to diseases and may destroy the aesthetic beauty of school environments because the vegetation will look dry laden among other concerns.

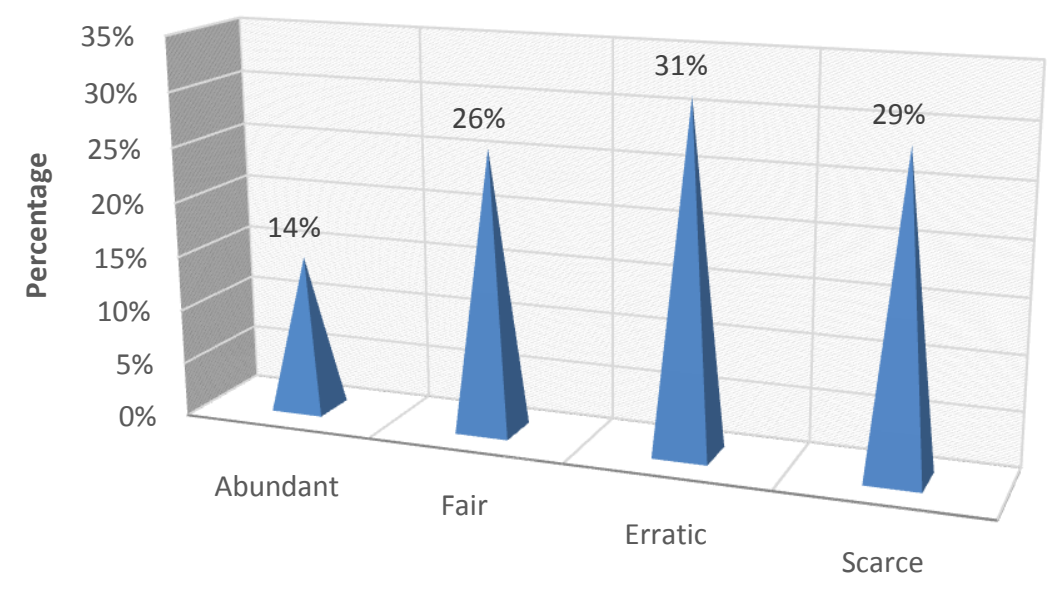

State of water supply

Figure5. State of water supply in school 
As noted in figure 5, water supply in selected schools of Chibombo district of Zambia was mainly erratic in supply (31\%) and scarce (29\%). This poor supply of water in schools could lead to diarrheal diseases and this can affect pupils and staff. This is in agreement with World Health Organisation (2004) who estimated that $88 \%$ of diarrheal disease is caused by unsafe water supply, and inadequate sanitation and hygiene. Most selected schools in Chibombo district lacked quality drinking water and sanitation facilities and had facilities that were inadequate in both quality and quantity. This could make pupils, staff and visitors vulnerable to environmental health hazards.

\section{(d) Safety status of playgrounds}

This study also investigated the safety status of play grounds in selected schools of Chibombo district. This is because playing in schools is key to physical, mental, intellectual and social well being of pupils. It impacts hugely on almost every developmental aspect of pupil's lives holistically and with multifaceted ways. The respondents in schools rated the status of play grounds in selected schools of Chibombo district of central Zambia. Their responses were as presented in figure 6 below.

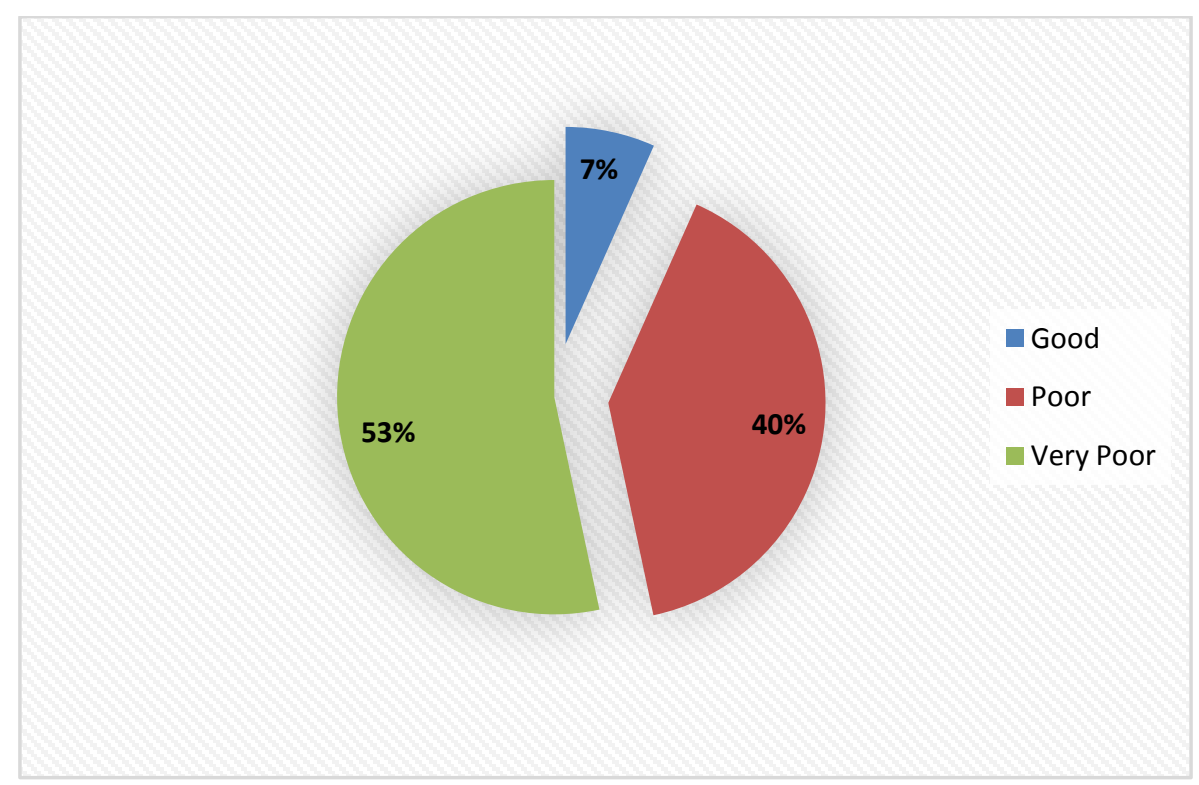

Figure6. Safety status of playgrounds

Source: (Field data, 2014)

As presented in figure 6 above, more than half of the respondents $(53 \%)$ noted that playgrounds were poor. $40 \%$ rated the safety status of school playgrounds as very poor while $7 \%$ rated safety status of playgrounds as good. Playgrounds in schools put enormous positive impacts on children's development and learning. It provides pupils with the leisure facilities to make learning livelier and make friends. School playgrounds play important role in pupils' daily life for fulfilling their interest, development and learning needs. For this reason, psychologists and educators consider school playgrounds as important venues for children's social and cognitive development" (Pellegrini, Davis \& Jones, 1995). However, as noted from figure 6, playgrounds in selected schools of Chibombo district were not safe enough for pupil's interaction and play. The playgrounds were not appealing and inviting. They were rough and generally of poor quality. This state of affairs could expose pupils and staff to injuries and reduce attendance rates. This poor state of playgrounds could also deter pupils' social and cognitive development.

\section{(e) Safety and health status of dormitories}

This study also assessed safety and health status of dormitories in selected schools of Chibombo district of central Zambia. This is because dormitories are one of the most used physical infrastructures in boarding schools. Pupils spend the longest continuous period of time in a day in dormitories, apart from classrooms. Therefore, it is important to keep dormitories clean, well lit and properly ventilated. Pupils, teachers and auxiliary staff in selected schools of Chibombo district rated safety and health status of dormitories as presented in table 1. 
Table1. Safety and health status of dormitories

\begin{tabular}{|c|c|c|c|c|c|c|c|c|c|c|c|c|}
\hline & \multicolumn{4}{|c|}{ Pupils } & \multicolumn{4}{|c|}{ Teachers } & \multicolumn{4}{|c|}{ Auxiliary staff } \\
\hline & \multicolumn{2}{|c|}{ Yes } & \multicolumn{2}{|c|}{ No } & \multicolumn{2}{|c|}{ Yes } & \multicolumn{2}{|c|}{ No } & \multicolumn{2}{|c|}{ Yes } & \multicolumn{2}{|c|}{ No } \\
\hline & Freq. & $\%$ & Freq. & $\%$ & Freq. & $\%$ & Freq. & $\%$ & Freq. & $\%$ & Freq & $\%$ \\
\hline $\begin{array}{c}\text { Whether dormitory } \\
\text { spaces were adequate }\end{array}$ & 8 & 40 & 12 & 60 & 5 & 28 & 13 & 72 & 3 & 25 & 9 & 75 \\
\hline $\begin{array}{c}\text { Whether lighting was } \\
\text { appropriate }\end{array}$ & 10 & 50 & 10 & 50 & 6 & 33 & 12 & 67 & 6 & 50 & 6 & 50 \\
\hline $\begin{array}{l}\text { Whether ventilation } \\
\text { was appropriate }\end{array}$ & 7 & 35 & 13 & 65 & 6 & 33 & 12 & 67 & 4 & 33 & 8 & 67 \\
\hline $\begin{array}{c}\text { Whether dormitories } \\
\text { were kept clean }\end{array}$ & 9 & 45 & 11 & 55 & 8 & 44 & 10 & 56 & 7 & 58 & 5 & 4 \\
\hline
\end{tabular}

Source: (Field data, 2014)

As presented in table 1 above, dormitory spaces for pupils in boarding schools were not enough. Enrollment in boarding schools was not tied to availability of bed spaces. The results also show that dormitories were not kept as clean as expected. Moreover, lighting and ventilation in dormitories was generally poor. The researchers observed that, in selected boarding schools under study in Chibombo district, dormitories doors had no grills. The dormitories were also not disability friendly since they had no ramps in place. In most boarding schools under study, windows had grills and lacked "emergency exit" doors that could hinder meaningful evacuation if pupils encountered any danger while in dormitories. This study established that management in schools still had a lot to do in terms of improving safety and health of dormitories.

\subsection{Safety and Health Challenges in Selected Schools of Chibombo District of Central Zambia}

This study also established safety and health challenges faced by stakeholders in selected schools of Chibombo district of Central Zambia. In the context of this study, knowledge of safety and health challenges faced by schools would help in coming up with sustainable mitigation measures. The responses from stakeholders were as presented in the table 2 below.

Table2. Safety and health challenges in selected schools of Chibombo district of central Zambia

\begin{tabular}{|c|c|c|}
\hline Safety and health challenges & Frequency & Percentages (\%) \\
\hline Lack of perimeter fencing & 12 & 24 \\
\hline Poor state of physical infrastructure & 9 & 18 \\
\hline Lack of safety and health training & 8 & 16 \\
\hline Poor sanitary conditions & 8 & 8 \\
\hline Lack of firefighting equipment & 4 & 18 \\
\hline Poor waste management & 9 & 100 \\
\hline Total & 50 & \\
\hline
\end{tabular}

Source: (Field data, 2014)

As presented in table 2 above, $24 \%$ of respondents bemoaned lack of perimeter fencing as a challenge to safety in schools. $18 \%$ of respondents noted that schools were not managing waste properly, $16 \%$ bemoaned lack of safety and health training. Others sited poor state of physical infrastructure (18\%), poor sanitary conditions (16\%) and lack of firefighting equipment $(8 \%)$.

As noted from the responses, researchers also noted that most schools were not fenced. This lack of fencing meant that there was no proper control of entry in and out of the schools. This could expose schools to certain levels of insecurity because it was difficult to know and identify intruders on campus. Perimeter fencing in schools may not only provide adequate protection, but also add to aesthetic beauty of school environment. This is in correlation with Hanover research (2013) arguing that appropriate fencing supports the security-enhancing principles of the crime prevention through environmental design. Fencing school campuses also help define ownership of given territory. Fences also help demarcate playground areas and help regulate pedestrian and vehicle traffic in school campuses.

Poor physical infrastructure was also noted by respondents as posing challenge to safety and health in selected schools of Chibombo district of central Zambia. The researchers also observed that most schools under this study had poor state of physical infrastructure. Classrooms, sanitation 
infrastructure, libraries, dining halls and laboratories generally needed renovations. This poor state of physical infrastructure in schools under this study could affect the teaching and learning process. Instead of concentrating on teaching and learning, pupils and staff may shift attention to their individual safety and health. This kind of scenario may even lead to poor attendance and retention of both pupils and staff in these schools. This is in correlation with Olutola (1982) who noted that, the availability of the school buildings and other plans contribute to good academic performance as they enhance effective teaching-learning activities. This is also supported by Ayeni and Adelabu (2011) who noted that the school and other stakeholders in education should effectively collaborate and contribute significantly towards the development of learning infrastructure and environment, so as to create a more conducive working environment for a sustainable high-quality education assurance practices in secondary schools.

Stakeholders in the schools under this study bemoaned lack of safety and health training among stakeholders. Teachers, pupils and auxiliary staff were not trained in safety and health issues. This meant that they did have adequate knowledge and skills necessary to handle safety and health issues in their respective schools. This could expose the school to risks of insecurity and unhealthy conditions, especially where technical knowhow was needed. This is in correlation with Hughes and Ferrent (2011) who stress the importance of safety training to ensure that personnel understand their responsibility and accountability for a safety and healthful workplace.

Schools under this study had poor sanitary conditions according to stakeholders. This was also noted by the researchers during the survey of these schools. Toilets and ablutions were in poor conditions as can be seen in picture 1 . Moreover, water reticulation was poor in most schools surveyed. This state of affairs could expose pupils, staff and visitors to risks of waterborne diseases. This could consequently affect learning and teaching in general by reducing attendance and retention rates as explained by the conceptual framework in this study. The foregoing argument is supported by Baghri and Wilson (2004) who argue that safe water and environmental sanitation services, that is, waste facilities are vital for people's dignity and health and are especially important in ensuring the healthy development of children.

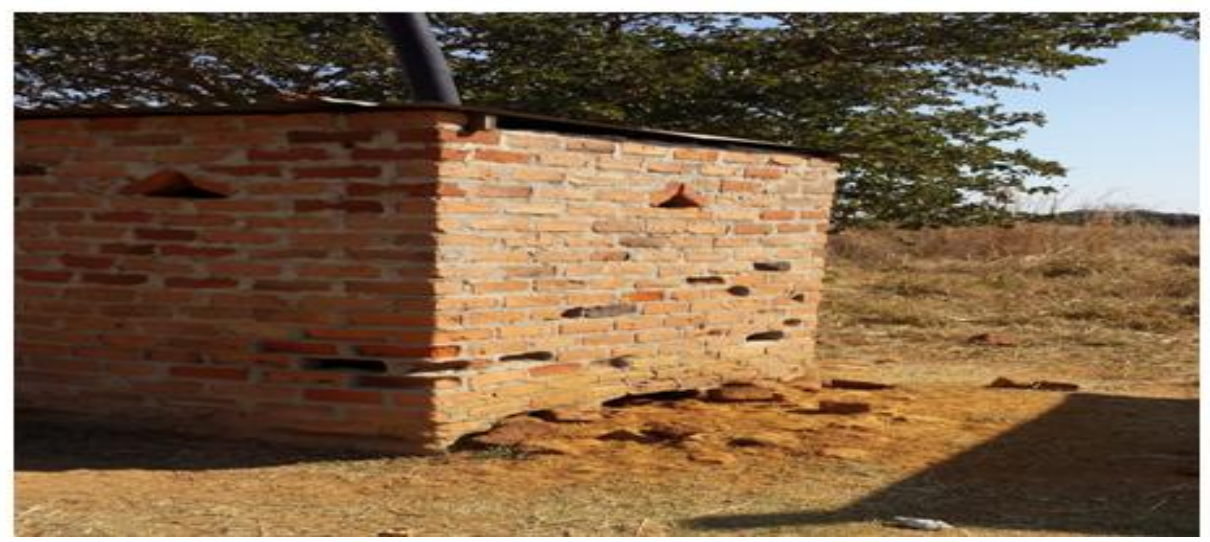

Picture1. A School pit latrine vandalised by pigs following the salty urine

Source: (Field data, 2014)

Most schools surveyed in this study lacked firefighting equipment. This was a concern for some stakeholders in the selected schools of Chibombo district of central Zambia. The researchers also noted that schools under this study had no fire extinguishers, fire horse reels and fire buckets among other firefighting equipment needed at a workplace. This state of affairs meant that the schools were exposed to risks of fire. It meant that in event that fire started, little could be done to extinguish it. Fire could therefore destroy school property, destroy aesthetic beauty of school environments and destroy fauna and flora. The Florida Department of Education (FDoE, 1993) also recommends that firefighting equipment should be located in main circulation paths of schools to help quench fires in case of an emergency.

Poor waste management was also noted as one of the safety and health challenges in selected schools of Chibombo district of central Zambia. According to stakeholders, waste was poorly managed in schools under this study. Mostly, litter was swept, collected and put in rubbish pits. Incineration was the common method of managing waste as shown in picture 2 . 


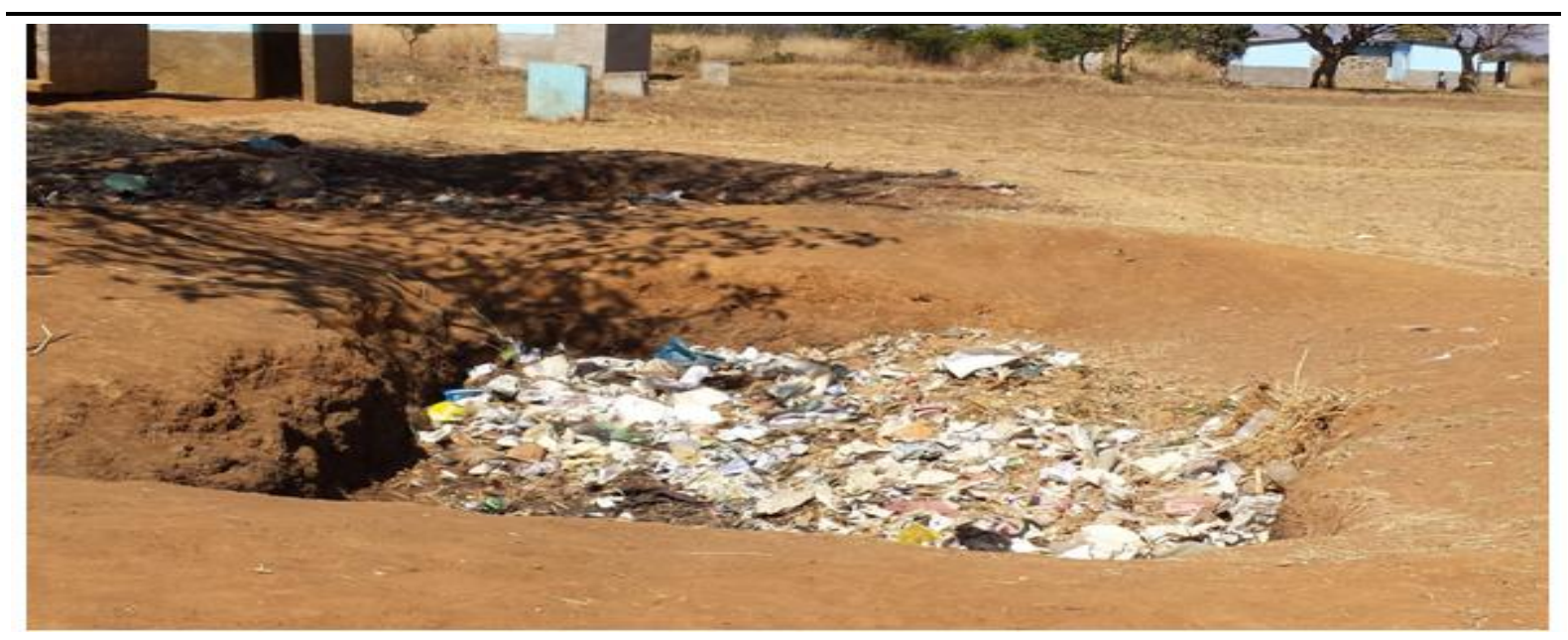

Picture2. Rubbish pit at one of the schools under study

Source: (Field data, 2014)

\section{Proposed Sustainable Mitigation Measures to Address the Challenges of SAfety and Health Identified in Selected Schools of Chibombo District of Central Zambia}

It is clear that the surveyed schools in this study had significant challenges in safety and health management. Therefore, this study proposes the following sustainable mitigation measures in order to solve the challenges identified:

(a) The schools should come up with a safety and health committee that should spear head safety and health programmes. This is in correlation with the Occupational Health and Safety Act of 2010 of the Republic of Zambia Part III, section 11 which records that a workplace of ten or more persons shall establish a health and safety committee.

(b) The schools should ensure that pupils and staff are trained and oriented in school safety and health management issues.

(c) The schools should partner with the local authorities to improve water reticulation and the state of sanitation infrastructure.

(d) All schools should have perimeter fencing to control entry in and out of the school's campus and also to guard ownership of the premises.

(e) Schools should also carry out risk assessments and audits to identify safety and health hazards and suggest control measures.

(f) All schools under survey should install firefighting equipment to help in the management of fire safety issues.

(g) Schools should draw safety and health policies in line with their school requirements.

(h) School-community relations should be improved if security issues are to be enhanced.

\section{Conclusion}

This study has explored safety and health issues in selected schools of Chibombo district of central Zambia. The surveyed schools had significant safety and health challenges. The safety and health status of the schools under this study can generally be termed as poor. There is a lot to be done in schools to improve on safety and health status. In order to improve safety and health status of schools under this study, there is need for concerted effort from all stakeholders. Pupils and staff should also improve their safety culture so as to improve the general schools' safety climate. This study recommends that the government should provide safe and health school environments through appropriate frameworks, guidance and legislation in order to improve safety and health status of schools. 


\section{REFERENCES}

Ayeni, A. J. \& Adelabu, M.A. (2011). Improving learning infrastructure and environment for sustainable quality assurance practice in secondary schools in Ondo State, South-West, Nigeria. International Journal of Research Studies in Education 2012 January, Volume 1 Number 1, 6168

Baghri, S. \& Wilson, T. (2004). Plan's Approach To Water And Environmental Sanitation. Working Paper Series. Surrey, U.K.: Plan Limited.

Cash, C.S. (1993). Building Condition and student achievement and behaviour. Unpublished doctoral dissertation: Virginia Polytechnic and state University, Blacksburg

Cohen, L., \& Manion, L. (1994). Research methods in education. (4th ed.) London: Routledge.

Creswell, J.W. (2003). Research design: Qualitative, quantitative, and mixed methods approaches. (2nd ed.) Thousand Oaks: Sage.

Fentiman, A., Hall, A. and. Bundy, D . (1999). "School enrolment patterns in rural Ghana: a comparative study of the impact of location, gender, age and health on children's access to basic schooling. "Comparative Education, 35(3): 331-349.

Florida Department of Education, (1993). Safe School Design Guidelines. Florida: The Florida Centre for Community design + Research

Hanover Research .(2013). School Fencing: Benefits and Disadvantages $1750 \mathrm{H}$ Street NW, $2^{\text {nd }}$ Floor Washington, DC20006

Hunghes, H and Ferrent, E. (2011). Introduction to Health and Safety at Work. The handbook for the NEBOSH National General Certificate. Rutledge, Taylor and Francis Group, London

Lidonde, R.(2004). Scaling up school sanitation and hygiene promotion and gender concerns. "In: School Sanitation and Hygiene Education Symposium. The Way Forward:Construction is Not Enough!

McLeod, S. A. (2014). Maslow's Hierarchy of Needs. Retrieved from www.simplypsychology.org/ maslow.html

Mertens, D.M. (2005). Research methods in education and psychology: Integrating diversity with quantitative and qualitative approaches. (2nd ed.) Thousand Oaks: Sage.

Mubita, K. (2016). Safety and Health Issues at Sefula Secondary School of Western Zambia. International Journal of Humanities Social Sciences and Education (IJHSSE) Volume 3, Issue 9, September 2016, PP 91-99

Mwangi, J.W. (2008). A Survey of the status of Disaster Preparedness in Public Secondary Schools; A Case of Kiharu Division, Muranga District.Unpublished Med Thesis. Kenyatta University.

Oluremi, O. F. (2005). Creating a friendly school learning environment for Nigerian children. European Scientific Journal April edition vol. 8, No.8: 138-147

Olutola, A. (1982). School planning and maintenance introduction to educational planning. S Adesina (ed). Ile-Ife University of Ife Ltd, p. 210-219

Pellegrini, A. D., Davis P. \& Jones, I. (1995). The Effects of Recess Timing on Children's Playground and Classroom Behaviours. American Educational Research Journal Winter 1995, Vol. 32, No. 4, pp.845-864

Republic of Zambia. (2010). Occupational Health and Safety Act; Part III, Section 11

Romina, A. (2014). Students' perception of the condition of their classroom physical learning environment and its impact on their learning and motivation. College Student Journal; Winter2014, Vol. 48 Issue 4, p716

Squelch, J. (2001). Do Schools governing bodies have a duty to create Safe Schools? An educational Law perspective. Perspectives in Education 19:137-149.

UNESCO. (2004). What Else Can Schools Do To Improve The School Environment? Paris: UNESCO 


\section{AUTHORS' BIOGRAPHY}

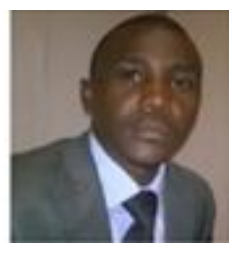

Kaiko Mubita, is a lecturer in Geography and Environmental Education at the University of Zambia. He is also a PhD student in Environmental Education at the same institution. His research interests are in occupational health and safety, environmental hazards and disasters and Geography Education.

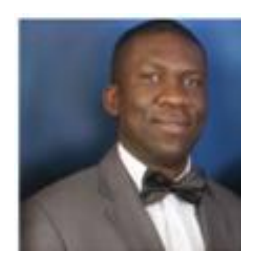

Timothy K. Phiri, is an Environmental Education lecturer in the Department of Language and Social Sciences Education, School of Education at the University of Zambia. His research interests are in Environmental Sustainability, Occupational health and safety and Mindset and Behavioural Change.

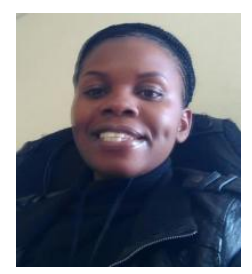

Pauline N. Monde, is a lecturer at the University of Zambia in the Department of Language and Social Sciences Education. She is currently enrolled for $\mathrm{PhD}$ in Environmental Education at the same institution. Her areas of research interests include but not limited to Environmental Management, Environmental Governance and Ecological issues.

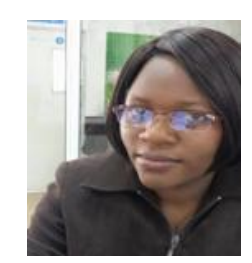

Steria M. Simooya, is a Lecturer at the University of Zambia in the Department of Language and Social Sciences Education. Her areas of research interests include but not limited to Environmental Management, Environmental Journalism and Environmental Education. 